\title{
CONSIDERATIONS FOR HOMOGENIZING ALLOYS
}

\author{
Paul D. Jablonski ${ }^{1}$ and Jeffrey A. Hawk ${ }^{1}$ \\ ${ }^{1}$ National Energy Technology Laboratory \\ 1450 Queen Avenue SW, Albany, OR 97321 United States
}

Keywords: Advanced Ultra Supercritical, Steam Turbine, Superalloy, Casting, Homogenization

\begin{abstract}
Chemical inhomogeneities result naturally as a by-product of alloy solidification. Thermal or thermo-mechanical treatments are often used to reduce these inhomogeneities. The question remains exactly how to achieve this and to what level. If the chemical inhomogeneity profile is known a-priory, kinetic modeling software such as DICTRA (Diffusion Controlled TRAnsformations) can be used to model the homogenization kinetics of an alloy. In this study, the Scheil module within the ThermoCalc software was used to predict the as-cast segregation of alloys. The segregation profiles were read into DICTRA to refine the homogenization heat treatment of the alloys. The thermodynamic and kinetic modeling of the computationally predicted heat treatment and microstructure, and subsequent experimental verifications on real castings is presented along with a set of decision criteria.
\end{abstract}

\section{Introduction}

Solidification is a process whereby liquid metal freezes. However, during solidification some solute elements in the liquid metal prefer to remain in the liquid phase while other elements preferentially diffuse to the solid phase. Take for example the case of nickel-base alloys. During solidification from the melt, this separation causes chemical heterogeneity in the solidified structure with a significant fraction of $\gamma-\gamma^{\prime}$ eutectic at the interdendritic region [1-3]. It is, generally, accepted that $\mathrm{Co}, \mathrm{Cr}, \mathrm{W}$, and Mo segregate preferentially to the dendrite cores, while $\mathrm{Ti}, \mathrm{Al}$ and Ta segregate preferentially to the interdendritic region [3], however, this may not always be the case. There are two important effects of this microsegregation in the solidified structure: (1) chemical heterogeneity and (2) microstructural heterogeneity. These effects directly affect long-term microstructural stability on the one hand and mechanical properties on the other.

In heat resistant alloys, for example, the second effect is the most important as long-term exposure can lead to undesirable phases forming much sooner than expected with the concomitant breakdown of those segments of the microstructure responsible for strength, creep resistance, grain size control and oxidation resistance. For the specific case of commercial $\gamma^{\prime}$ strengthened nickel superalloy, and due to segregation of specific elements to the interdendritic region, the eutectic $\gamma^{\prime}$ precipitates in these regions tend to be coarse and irregularly shaped. Because the $\gamma-\gamma^{\prime}$ interface plays a role in deformation behavior due to its interaction with dislocations as well as in developing creep strength, it is important to form uniform and fine $\gamma^{\prime}$ precipitates that have a spherical or cuboidal morphology with coherent, or semi-coherent, interfaces, otherwise properties such as creep strength are degraded. Consequently, it is very important to completely homogenize the alloy before solution heat treatment and subsequent aging for strength by forming a fine array of $\gamma^{\prime}$. 
Heterogeneity in chemistry in the solidified structure can also lead to local chemical instabilities within the as-heat treated and/or as-processed microstructure. For example, again using nickel superalloys, in this case single crystal turbine airfoils, dendrite cores in the solidified structure are typically rich in $\mathrm{Cr}$ and $\mathrm{Mo}$, and as a consequence these regions become the preferred locations for the formation of TCP (topologically close packed) phases, which by their very nature offer no beneficial high temperature strength improvements $[3,4]$.

To promote chemical homogeneity within the microstructure, and eliminate coring and other undesirable chemistry based solidification artifacts, heat resistant alloys must undergo a thorough homogenization treatment prior to any subsequent heat treatment activity, be it solutionizing for nickel superalloys, austenitizing or normalizing for steels, or subsequent precipitation aging heat treatment to facilitate strength improvements in other alloy system. In many cases, the solution heat treatment can be skipped if the homogenization heat treatment temperature and cooling rates were adequate.

It has been common practice to homogenize heat resistant castings, especially single crystal and directionally solidified ones used in the land-based and aero-engine turbine industries. It is less common to think of applying homogenization practice to wrought alloys, mainly because it is felt that the thermo-mechanical processing (TMP) involved in breaking down the cast microstructure as it is shaped into component form suffices. However, newer heat resistant alloys, both martensitic steels for fossil energy applications and solution strengthened and low volume fraction $\gamma^{\prime}$ strengthened nickel superalloys, make significant use of refractory and transition elements to solution strengthen the matrix and develop complex carbides for grain size control and long-term microstructure stability. The refractory elements by their very nature, for example, segregate during solidification from the melt and either radically partition or diffuse very slowly in the solidified alloy. Consequently, one can envisage a solidified structure made up of the matrix formulation, which is most probably not the composition desired because the refractory elements are still located within the dendrite cores or in the interdendritic regions. One can thermo-mechanically manipulate the alloy, i.e., the matrix and the associated segregated regions, and do no more than move these regions around relative to one another. In some instances, depending upon the type of deformation process, these refractory element-rich regions may have their distance to another refractory element-rich region reduced in certain directions but increased in others. For those cases there is insufficient time during subsequent TMP steps for much, if any, diffusion of the refractory elements away from their element-rich local region to occur. Utilizing a one hour normalizing sequence after TMP for martensitic heat resistant steel, for example, does little to further disperse these hard to diffuse refractory elements.

For complex single crystal nickel superalloys, or nickel superalloys in general, homogenizationsolutionizing has been a very complicated process and is very equipment intensive, especially when a new alloy formulation is under development. For these alloys, it is particularly difficult to identify the solvus and solidus temperatures in the as-solidified alloy using experimental techniques like differential scanning calorimetry (DCS). Line broadening typically occurs during DSC scans for the corresponding endothermic and exothermic peaks as a result of chemical heterogeneity in the microstructure $[3,5-6]$. Part of the problem can be traced to heating and/or cooling rates used during DSC where the phase transformation temperature can vary depending on that scan rate. The exact temperature for the solvus and solidus can also vary with respect to global and local degrees of homogenization [6-7]. 
Complicating the problem in nickel superalloys is that eutectic $\gamma^{\prime}$ is very difficult to dissolve because it has a coarse, blocky morphology with low surface area per unit volume ratio. Therefore, the eutectic $\gamma^{\prime}$ precipitate dissolves very slowly into the surrounding $\gamma$ matrix [8]. Another complication arises due to highly segregated solidified microstructure having a local solidus temperature in the interdendritic region, which can be significantly lower than the "average" solvus temperature within the dendrites. If, for example, a super-solvus homogenization-solution heat treatment combination is used, the risk of localized melting in these regions is elevated, and if melting occurs, complete solutionizing is nearly impossible [3]. Trying to identify and avoid local incipient melting in the interdendritic region due to low local solvus temperature is the most challenging aspect of arriving at a comprehensive homogenization (and then solutionizing) heat treatment for nickel base superalloys. Steels pose a slightly different problem because of the change in phase as a function of the homogenization temperature.

It was mentioned in passing that thermal analysis (DSC in particular) has been traditionally used to identify phase changes in these alloys. There are many problems inherent with the use of this technique. However, some of these problems can be minimized with careful attention to experimental detail. The main issue that confounds easy resolution is local enriched regions and the change in the local solvus temperature. Using DSC to develop a series of complex heat treatments requires careful melting experiments followed by equally careful microscopy to identify changes in the chemical composition of the interdendritic regions and dendrite cores that might have altered the local solvus temperature. This can be particularly difficult because the analytical tools available are not sensitive enough to just determine the local chemistries from those regions. As a consequence there will always be a degree of uncertainty in these measurements, leading to a lengthy trial and error approach to eliminating the segregation in the alloy.

Conversely, thermodynamic and kinetic simulation software and databases, while not perfect, have evolved quite significantly over the past 10 years and now offer a potential time saving approach to homogenization and solutionizing (if needed) heat resistant alloys. Given the complex nature of these heat resistant alloys, a computational approach has become a necessary tool in making sure the formulated alloy contains the requisite phases in the appropriate fractions as well as providing guidance in its process history, especially heat treatment. At NETL, ThermoCalc and DICTRA have been utilized in a carefully prescribed algorithm to homogenize complex nickel-base superalloys as well as austenitic, martensitic and ferritic steels. Utilizing this approach has led to a high degree of homogenization for solid solution strengthened cast nickel superalloys $\left(230,617\right.$ and 625) as well as $\gamma^{\prime}$ strengthened nickel superalloys (105, 263, 740,282 and Waspaloy). Given this success, the homogenization sequence has been applied to every heat resistant alloy produced at NETL with very good results.

This paper will detail certain aspects of the approach to nickel superalloys. Discussion as to effectiveness will be provided through microscopy of the microstructures and mechanical property results, primarily through measurement of the creep rupture life.

\section{Background}

The simplest instability in a metallic microstructure is the one produced by a non-uniform distribution of solute within an otherwise stable single phase. Such a distribution always raises the free energy of the alloy and so it will decay to a uniform distribution at a rate determined by the thermodynamics and kinetics of diffusion [9]. The most usual cause of an inhomogeneous 
solid solution is the coring that results from solidification, as previously discussed. This results because any alloy that freezes over a range of temperature forms a solid with a range of compositions. The term "coring" describes the difference in the first bit of liquid to freeze during solidification (i.e., the core) from the last bit of liquid to freeze (i.e., the ring at the outer periphery surrounding the core). Alternatively, interdendritic segregation is more representative of situations where an imposed temperature gradient is absent. For this case, the solidified microstructure looks like a dendrite, or tree-like, structure where the segregated areas can be characterized by a length scale, or wavelength, associated with the dendrite arm spacing. This wavelength is a physical feature of great importance as is the diffusion coefficient. These specific alloy characteristics are then used in determining the kinetics of element diffusion needed to reduce the segregation associated with the interdendritic regions in the alloy [9-10].

The general approach to homogenizing an alloy [11-13] has typically started from the assumption that any segregation profile can be represented by a Fourier series of cosine functions of which the longest wavelength will be that of the dendrite arm spacing $d$. This Fourier component can be written in the following way:

$$
C(x)=C_{0}+C_{a} \cos (2 \pi x / d)
$$

Where $C_{0}$ is the average composition; $C_{a}$ is the amplitude; and $d$ is the fundamental wavelength, i.e., the dendrite arm spacing. In general there will also be a number of higher order harmonics associated with this cosine function, each of which will then decays at its own particular rate;

$$
C(x)=C_{0}+C_{a} \cos (2 \pi x / d) e^{-t / \tau}
$$

Where $\tau=\frac{4 d^{2}}{D \pi^{2}}$, and $D$ is the appropriate diffusion coefficient.

However, the higher order harmonics will, in general, have very short relaxation times compared to that of the fundamental cosine function. This means that the pattern of segregation will decay from the representative harmonic function to the simple cosine function of wavelength, $d$. Thus, the major factor determining the kinetics of homogenization will be the value of the fundamental relaxation time. It has been assumed in the literature that homogenization times of the order of $3 \tau$ (i.e., $12 d^{2} / D \pi^{2} \approx d^{2} / D$ ) will eliminate segregation almost completely. The general approach just described has been used qualitatively and quantitatively to homogenize alloys. Ward [14] and Weinberg and Buhr [15] found that exact agreement was not achieved.

Even given the importance of the subject very few investigations on the effect of homogenization on mechanical properties have been attempted. In a study by Ahearn and Quigley [16] it was discovered that room temperature ductility of cast steels improved steadily with homogenization as measured by the dimensionless homogenization parameter, $D t / d^{2}$, where $t$ was the homogenization time.

This early research on trying to associate the observed segregation in an alloy with some feature in the microstructure (i.e., dendrite arm spacing, $d$ ) has led to the following general rule of thumb approach: Produce a chilled thin cast structure with as fine a dendrite arm spacing as possible followed by heat treatment (homogenization) at as high a temperature as possible to give a maximum value for $D$. This would, in theory, give the shortest time for complete homogenization. But not everything can be cast in thin sections or chilled to create closely 
spaced dendrite arms [17]. The problem, of course, is to accurately define the temperature, or temperatures, to homogenize the alloy as well as the time needed at each temperature.

Casting large ( $>$ several tonne) or thick wall $(>100 \mathrm{~mm}$ ) ingots, such as usually found in the fossil energy industry, results in very slow cooling rates, leading to dendrite arm spacing that can reach, or exceed, $1 \mathrm{~mm}$. In cases such as these, and with a diffusion coefficient on the order of $10^{-12} \mathrm{~m}^{2} / \mathrm{s}$, and using the general approach described where homogenization time is roughly equal to $\left(d^{2} / D\right)$, the time for complete homogenization of the alloy would be approximately $10^{7}$ $\mathrm{s}$, or about 116 days [18]. To proceed in this manner is not practical from a commercial perspective.

If the final product form is to be something other than the cast structure, thermo-mechanical processing (TMP) of some type can be used to change the shape. It has been, and often still is, assumed that by heavily deforming the cast structure to reduce the section thickness as well as to alter the segregation wavelengths, the homogenization potential can be altered. A hypothetical case has been presented to support this [18]. In this example, an ingot of material is deformed through extrusion in the $\langle 110\rangle$ direction to $1 / R$ of its diameter. For simplicity, this results in a tetragonal shape with dimension: $R^{2}, 1 / R, 1 / R$. In this idealized example, two alternative directions with respect to the extruded material are explored, $\langle 110\rangle$ and $\langle 100\rangle$. From the perspective of dendrite arm spacing change, the spacing between dendrite centers in the (011) plane will be reduced by $1 / R$, and so the time for homogenization of structures on this plane will be reduced by $1 / R^{2}$. However, the periodicity in the $\langle 100\rangle$ direction will have its wavelength increased by $R^{2}$, and so the time for complete homogenization to occur will increase by $R^{4}$. Thus, the "average" situation will lie somewhere between these extremes. Consequently, after deformation the initial stages of homogenization may be accelerated while at the latter stages it very well may be greatly delayed. Very few investigations have been done to actually test this hypothesis. Those that have been done have been contradictory, with one supporting the assertion that deformation of the alloy accelerated homogenization [19] while another could find no significant effect [15]. A third study using well defined starting powders in a sintered powder metallurgy product form supported to some degree the deformation-homogenization assertions as stated previously [20].

Research at NETL originally focused on casting various nickel superalloy formulations for use as thick sections in Advanced Ultra Supercritical power plants. The goal was to produce relatively small castings that simulated slow cooling, and were thus representative of thick section casting found in valve chests and steam turbine rotor casings. Deformation processing for these components is not an option. Examination of the resultant cast structures confirmed that slow cooling was obtained as evidenced by the solidification macrostructure as well as the dendrite arm spacing. However, these castings were also segregated quite severely. Before evaluating mechanical behavior it was desired to reduce the segregated nature of the castings.

The specific approach developed at NETL to reduce the degree of segregation in nickel superalloy castings utilized simple microstructural measurements from the as-cast microstructure to scale the degree of segregation as predicted by the well-known Scheil-Gulliver approach. This information is considered within DICTRA and ThermoCalc to predict the chemical profile and then provide an estimate of the incipient melt temperature using these starting conditions after a subsequent given heat treatment step. This approach can accelerate the development of homogenization heat treatments for newly developed heat resistant alloys as well as optimize homogenization heat treatments for existing commercial formulations. Previous efforts had 
relied on the alloy solidifying from the melt as a single matrix phase. However, not all alloys solidify in this manner. For example, many Fe-based alloys begin to solidify with a BCC crystal structure and finish with an FCC structure. Other alloys start with an FCC structure and finish with a BCC structure. Still other alloys may form a significant amount of second phase such as carbide or other some other ordered phase. In this instance, characterizing only the matrix phase does not adequately capture the overall nuances of the local chemistries found in these alloys. The NETL computational approach calculates the incremental solid chemistry, i.e., the chemistry of each new addition to the solid from the overall amount of liquid and its chemistry as the alloy progresses from the initial stages of solidification through the point when all liquid is converted to solid. In this way, the "solids" from each increment are lumped together into an "overall chemistry" that can then be used to calculate the interdiffusion required to bring about homogenization. The description of the solid chemistry flows from that of the liquid as follows:

Chemistry just before first solid forms: $f_{s}=0=C_{0}$.

Chemistry when first solid forms:

$$
C_{s_{1}}=\frac{\left(C_{o}-f_{l_{1}} C_{l_{1}}\right)}{\operatorname{inc} f_{l}}
$$

Chemistry for each additional solid that forms is given by:

$$
C_{s_{1+i}}=\frac{\left(c_{o}-f_{l_{1+i}} c_{l_{1+i}}-\sum f_{l_{i}} c_{l_{i}}\right)}{\operatorname{inc} f_{l}}
$$

The variables are described as follows: $C_{0}$ is the overall alloy chemistry for each element; $C_{s_{1}}$ is the chemistry of the first solid to form; $C_{S_{1+i}}$ is the chemistry of the $s_{1+i}$ solid to form; $f_{l_{n}}$ is the fraction of $n^{\text {th }}$ liquid to form; $C_{l_{n}}$ is the composition of the liquid when the $n^{\text {th }}$ liquid forms; and inc $f_{l}$ is the incremental fraction of liquid that forms when the $n^{\text {th }}$ liquid forms. To homogenize an alloy to a high degree requires multiple steps based on redefining this "overall chemistry" for each homogenization step (i.e., specific temperature and time at temperature increment) until the required degree of homogenization is reached.

\section{Experimental Details}

In this study, the Scheil Module of the thermodynamic modeling software ThermoCalc [21] was utilized to predict the extent of chemical microsegregation present within the alloys under study. Whenever possible, the actual measured chemistry of the solidified cast alloy was used. Close attention was given to potent melt point suppression elements such as $\mathrm{C}, \mathrm{Si}$ and $\mathrm{Mn}$. Based upon the chemical segregation predicted, the kinetic modeling software DICTRA [22] was used to design an optimized homogenization heat treatment that would flatten out the concentration profile of each alloying element within the dendrites of the matrix.

The Scheil Module and Ni-database [23] of the ThermoCalc software was used to predict the non-equilibrium solidification range of each alloy. The Scheil Module is an implementation of the Scheil-Gulliver Model [24,25], which assumes that diffusion occurs infinitely fast within the liquid phase, and that there is no diffusion in the solid phases that form. The analytical Scheil equation is commonly derived for an idealized system in which the liquidus and solidus are linear with respect to composition. If this is true, then $C_{s} / C_{l}=k$ where $C_{s}$ is the composition 
of the solid and $C_{l}$ is the composition of the liquid at a given temperature. When an incremental amount of solid $\left(d f_{s}\right)$ forms, $C_{s} d f_{s}$ solute transfers from the liquid to the solid. As a result, the incremental change in the liquid composition is given by:

$$
d C_{l}=\left(C_{l}-C_{s}\right) d f_{s} /\left(1-f_{s}\right)
$$

This equation can be integrated to describe the composition of the liquid as a function of fraction solid $\left(f_{s}\right)$ formed:

$$
C_{l}=C_{o}\left(1-f_{s}\right)^{(k-1)}
$$

In the more complicated case in which the liquidus and solidus curves are not linear, one would need to describe $C_{s}$ and $C_{l}$ analytically and integrate Eq. (5) accordingly. The Scheil Module within ThermoCalc calculates $\Delta f_{s}, \Delta C_{s}$ and $\Delta C_{l}$ in a user-selected increment of temperature until a predetermined amount of liquid remains. Fast diffusing elements such as B, C, N, and $\mathrm{O}$ can be allowed to back-diffuse within the solid, but this was not considered in the present case. The default results obtained from the Scheil simulation for a given alloy are the amount of solid phase formed versus solidification temperature. Not only does this show how the solidification sequence progresses, it also shows the phases that develop (many are non-equilibrium), as well as the solidification temperature range. After this data is obtained, the amount of each alloying element in a given phase present can be determined. In the case of these alloys, the weight fraction of each of the alloying elements in the liquid phase was then calculated as a function of temperature. The liquid phase chemistry was used to calculate the overall solid phase chemistry as described by Eqs. (3) and (4). Thus, the chemical segregation that occurs in the solid across a secondary dendrite arm constitutes the undesired microsegregation that needs to be eliminated through an appropriate homogenization heat treatment. Standard metallographic techniques were used to measure the secondary dendrite arm spacing (sdas) of the castings. From these measurements, a value of approximately $1 / 2$ the maximum sdas was used as a conservative estimate of the required diffusion distance. The weight fraction of matrix phase was scaled to this distance and read into the DICTRA software, along with the chemistry profiles across the matrix phase.

Approximately $7 \mathrm{~kg}$ heats of the experimental nickel superalloy lots were formulated from high purity raw materials and melted and cast in a Vacuum Induction Furnace. The melts were cast with $50^{\circ} \mathrm{C}$ superheat above the ThermoCalc predicted liquidus temperature into $100 \mathrm{~mm}$ diameter round graphite molds. The mold was placed in a secondary container with loose-packed sand around the outside. The sand height was fixed to be above the final height of the solidified ingot in the mold to facilitate a slow cooling rate such as to mimic the cooling rate of larger sized castings of the same alloy. Commercial scale castings were also made by multiple methods, including VAR (vacuum arc remelting) and sand casting. The scale of those microstructures was subsequently measured using standard metallographic techniques and used as the scale of the matrix phase as previously described.

The microstructures of the castings were evaluated through standard metallographic techniques, including sectioning, grinding, polishing, and etching followed by optical microscopy. The sdas was measured using a line intercept method. A sample from the casting was subjected to the homogenization heat treatment developed utilizing the techniques outlined here. A side-by-side comparison of the as-cast and homogenized specimens was provided by mounting them together in the same metallographic mount, thus providing identical metallographic preparation 
conditions. Whenever possible, mechanical property testing, such as room and elevated temperature tensile tests as well as creep rupture tests, was performed on selected samples as well.

\section{Results}

At NETL a variety of alloys have been heat treated according to the computationally optimized homogenization technique presented here. In some cases multiple examples of the same alloy cast under similar conditions (and thus anticipated to have similar scaled microstructures) have been investigated. Likewise, in some cases the same alloy has been cast at small scale as well as larger scale, or perhaps by a different method (or both), thereby providing a range of sdas characteristic lengths. Several of these examples follow.

Haynes alloy 282 is a relatively new wrought Ni-based superalloy initially developed for the aerospace industry. The alloy has a nominal composition of $\mathrm{Ni}-19.5 \mathrm{Cr}-10 \mathrm{Co}-8.5 \mathrm{Mo}-2.1 \mathrm{Ti}-1.5 \mathrm{Al}$ with small amounts of $\mathrm{C}$ and $\mathrm{B}$ and prescribed limitations on the amounts of $\mathrm{Fe}, \mathrm{Mn}$ and $\mathrm{Si}$. Under the auspices of the NETL Program on Advanced Ultra Supercritical Turbine materials this alloy has been evaluated for thick section steam turbine casing and valve body components. These components, because of the size requirements, are most economically made by sand casting. Initial trial lots of Haynes 282 were cast into $100 \mathrm{~mm}$ diameter molds using the "enhanced" slow-cooling technique to emulate larger castings [26-27]. The cast Haynes 282 ingot was evaluated using the Scheil module within Thermocalc and then "homogenized" via computer simulation using DICTRA. Metallographic measurements showed the sdas varied between $47 \mu \mathrm{m}$ and $96 \mu \mathrm{m}$ in the $100 \mathrm{~mm}$ diameter castings. From these measurements, a value of $50 \mu \mathrm{m}$ (or $\sim 1 / 2$ the maximum sdas) was used as a conservative estimate of the required diffusion distance. As an example of the technique, the as-solidified profile for Mo is shown in Figure 1 along with a schematic representation of a dendrite.

Molybdenum is observed to segregate to the interdendritic region of this alloy. Note that the inhomogeneity is scaled to half of the sdas. Figure 2 shows the Mo profile in the as-cast state and after several simulated time steps at $1100^{\circ} \mathrm{C}$. This temperature was chosen because it was safely below the estimated non-equilibrium incipient melt temperature, $\sim 1167^{\circ} \mathrm{C}$. After running these simulations it was evident that even after $80,000 \mathrm{~s}(\sim 22.4 \mathrm{~h})$ at $1100^{\circ} \mathrm{C}$, the Mo has not been substantially homogenized. Evaluating the local chemistry after a shorter time step indicated that the incipient melt temperature has risen to approach the equilibrium incipient melt temperature. This fact can be used to advantage in this alloy to improve the efficiency of the homogenization cycle.

For example, after $10,000 \mathrm{~s}(\sim 2.8 \mathrm{~h})$ at $1100^{\circ} \mathrm{C}$ the incipient melt temperature has increased to $\sim 1245^{\circ} \mathrm{C}$, thus allowing the homogenization temperature to be safely raised as well. A second evaluation was made with $10 \mathrm{ks}$ at $1100^{\circ} \mathrm{C}$ followed by the remaining time at $1200^{\circ} \mathrm{C}$. See Figure 3 for details. In this case, it is quite evident that the efficiency of the homogenization cycle has greatly improved by incorporating a second, higher, temperature treatment. It should be noted that the choice of temperature margin between the homogenization cycle and the incipient melt point is somewhat arbitrary. Factors considered in the selection include the accuracy of the estimated incipient melt point (mainly dependent on the quality of the thermodynamic database and measurement of the sdas), furnace temperature control margin, and furnace temperature uniformity. Other considerations include maximum furnace temperature capability. The impact of the homogenization cycle on the microstructure is shown in Figure 4, which compares the ascast with the cast and homogenized microstructure. Clearly, the alloy exhibits less segregation 
after homogenization. Perhaps more important is the comparison between the homogenized and non-homogenized mechanical properties. Figure 5 show creep rupture performance of the ascast, cast and homogenized, and wrought product forms. While the homogenized castings compared favorably to the wrought material, the non-homogenized as-cast samples generally did not do as well in terms of creep rupture.

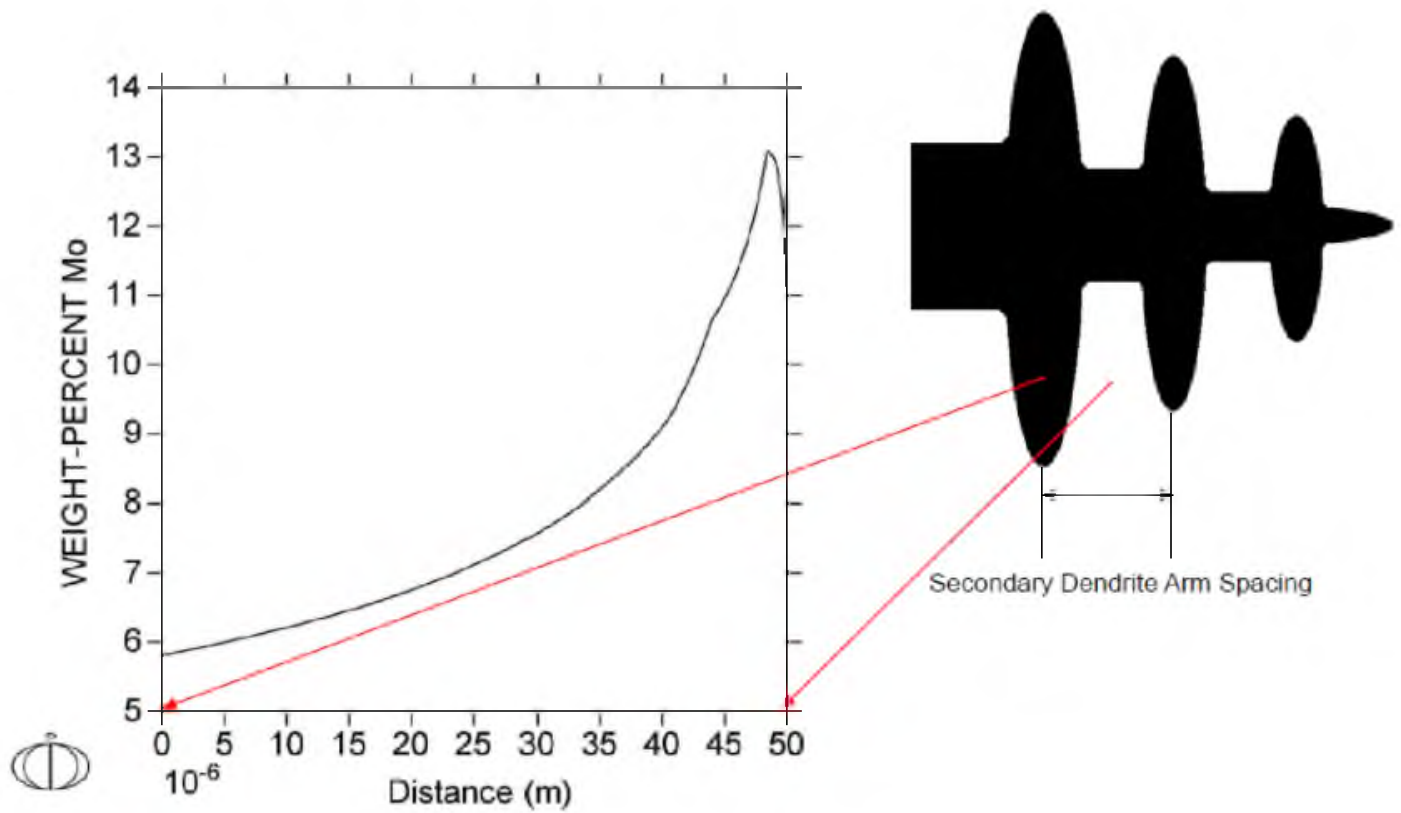

Figure 1: The as-solidified profile of Mo along with a schematic dendrite is shown above.

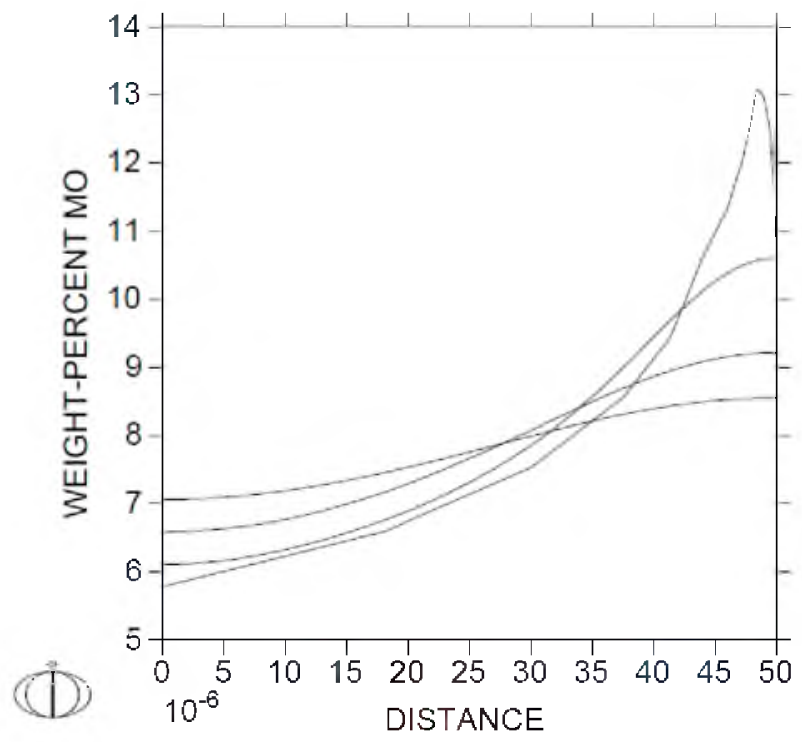

Figure 2: The Mo profile as-solidified and after $10 \mathrm{ks}, 40 \mathrm{ks}$, and $80 \mathrm{ks}$ at $1100^{\circ} \mathrm{C}$ is shown above (as time increases the profile approaches horizontal). Note that substantial inhomogeneity remains even after $80 \mathrm{ks}$ at $1100^{\circ} \mathrm{C}$. 


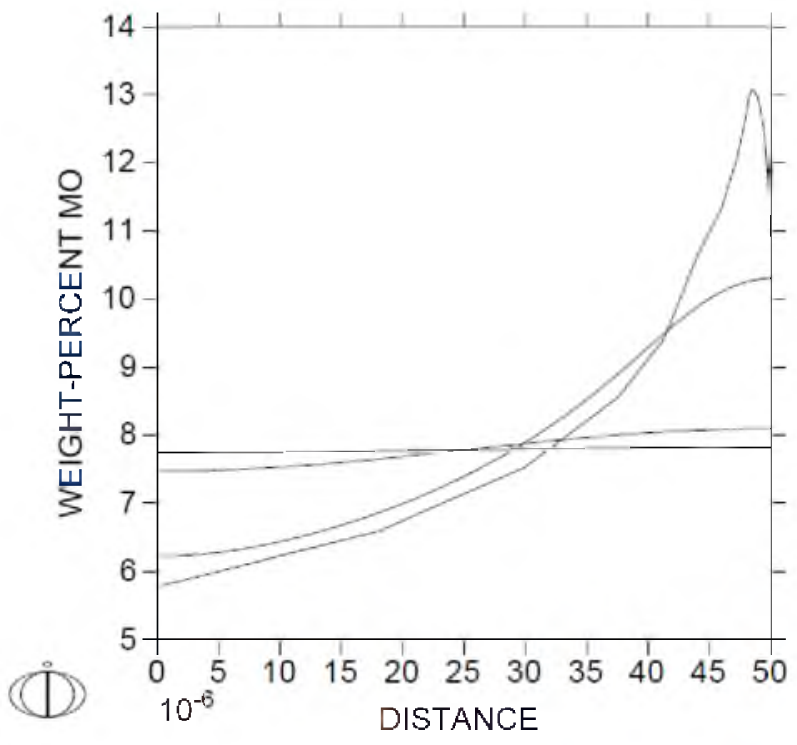

Figure 3: The Mo profile as-solidified and after $10 \mathrm{ks}, 40 \mathrm{ks}$, and $80 \mathrm{ks}$ total time is shown above (as time increases the profile approaches horizontal). After $10 \mathrm{ks}$ at $1100^{\circ} \mathrm{C}$ the simulation temperature was raised to $1200^{\circ} \mathrm{C}$. Note the substantial improvement in the Mo profile over the single temperature simulation (Figure 4).

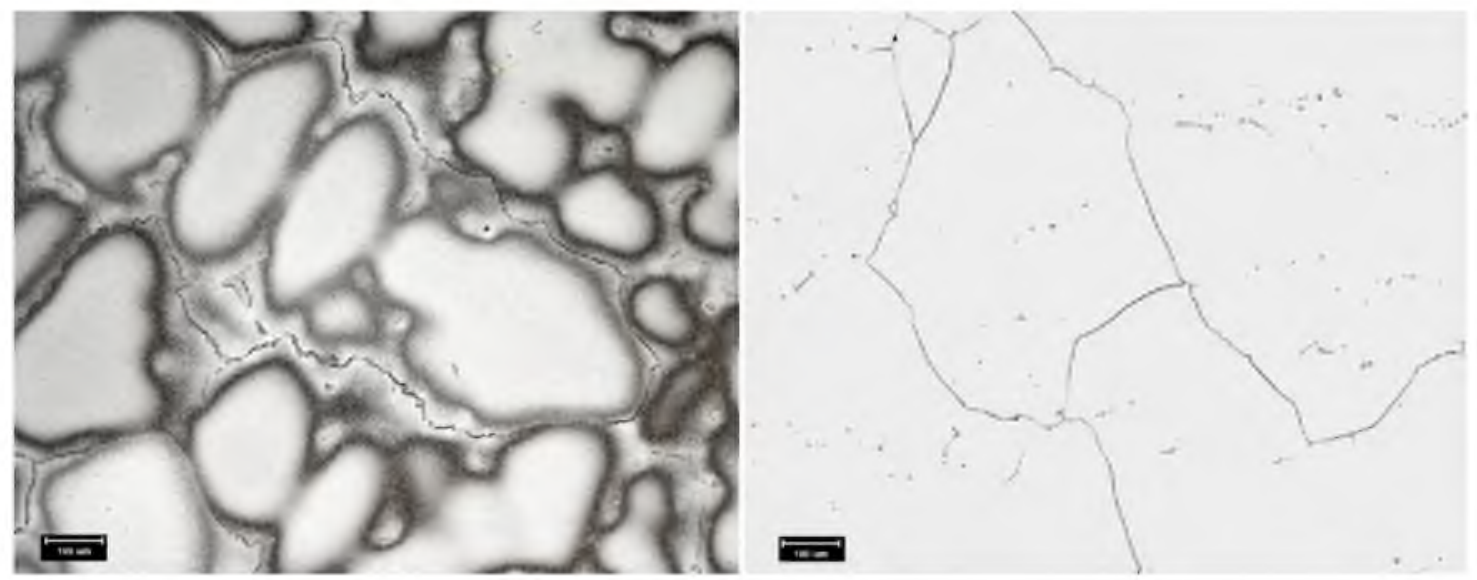

Figure 4: Examples of the as-cast (left) and homogenized (right) microstructure of Haynes 282 are shown above. Dendritic coring is clearly visible on the left while only grain boundaries and carbides are visible on the right. Note that these two samples were in the same metallographic mount and were prepared in an identical manner. 


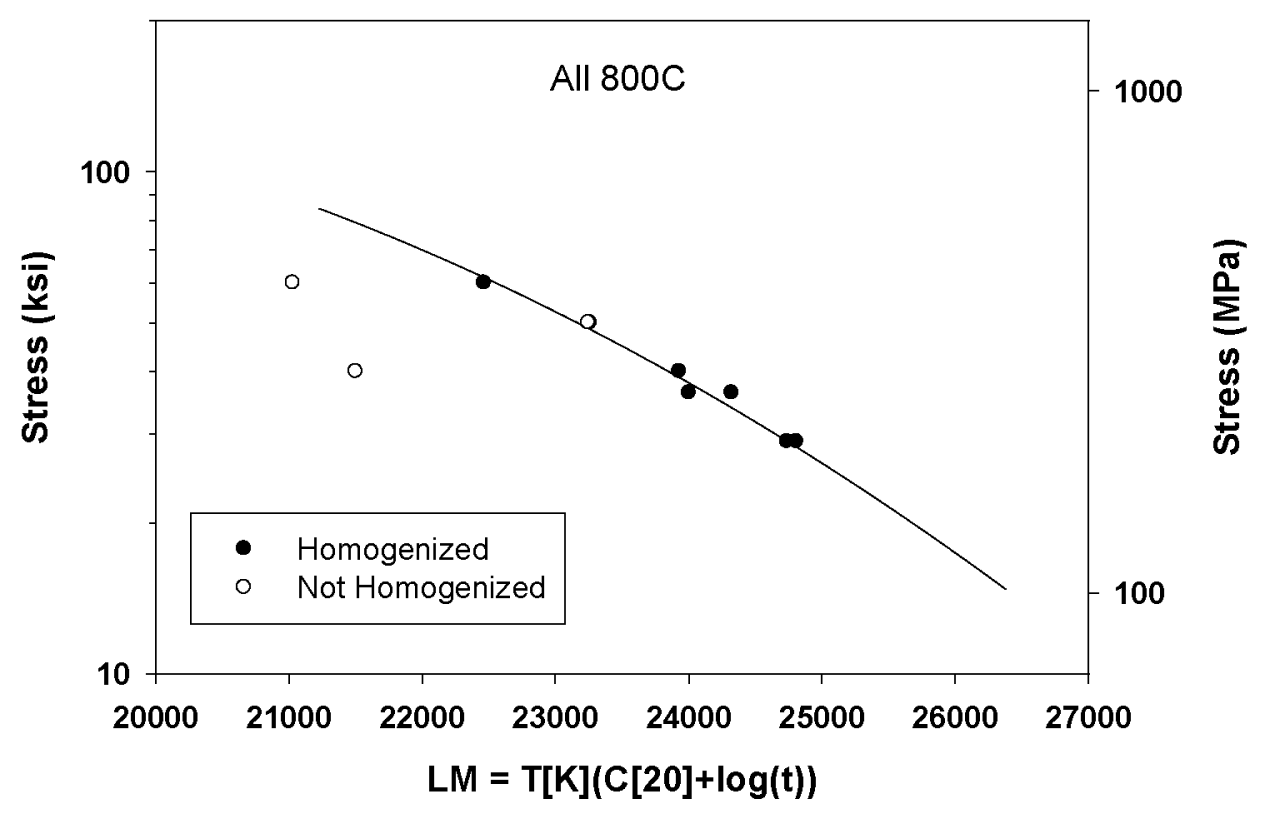

Figure 5: Larson-Miller plot that compares the as-cast (open circles) to cast and homogenized (solid circles) to wrought (solid line) Haynes 282 is shown above. Note that the cast and homogenized material compares favorably to wrought Haynes 282 creep rupture while these not homogenized generally do not.

The impact of microstructural scale is significant, if somewhat predictable. Figure 6 shows a plot of the predicted Mo simulation profile after homogenizing material with sdas of 100, 200 and $400 \mu \mathrm{m}$. It is clear that while modulation in the $100 \mu \mathrm{m}$ Mo profile has "flattened" (significant reduction in segregation), the same cannot be said for the coarser microstructures. Haynes 282 has been cast on a larger scale and the measured sdas was on the order of $200 \mu \mathrm{m}$. For this particular alloy simulation, 3 hours at $1100^{\circ} \mathrm{C}$ raises the incipient melt point to $1245^{\circ} \mathrm{C}, 1219^{\circ} \mathrm{C}$ and $1219^{\circ} \mathrm{C}$ for sdas of 100,200 or $400 \mu \mathrm{m}$, respectively. Thus, these results clearly show that it gets progressively more difficult to raise the temperature for castings that exhibit coarser microstructures with large representative sdas lengths. Some advantage can be gained by going to a higher temperature initially as this raises the incipient melt temperature sooner. However, for this alloy the equilibrium incipient melt temperature is only on the order of $1260^{\circ} \mathrm{C}$, so the upper furnace temperature can become the limiting homogenization processing factor. NETL has successfully homogenized large castings of this alloy using the following cycles:

(1) $1130^{\circ} \mathrm{C} / 3 \mathrm{~h}+1200^{\circ} \mathrm{C} / 3 \mathrm{~h}+1210^{\circ} \mathrm{C} / 14 \mathrm{~h}$

(2) $1100^{\circ} \mathrm{C} / 6 \mathrm{~h}+1200^{\circ} \mathrm{C} / 48 \mathrm{~h}$

(3) $1133^{\circ} \mathrm{C} / 4 \mathrm{~h}+1190^{\circ} \mathrm{C} / 8 \mathrm{~h}+1223^{\circ} \mathrm{C} / 30 \mathrm{~h}$

(4) $1125^{\circ} \mathrm{C} / 1 \mathrm{~h}+1160^{\circ} \mathrm{C} / 3 \mathrm{~h}+1190^{\circ} \mathrm{C} / 6 \mathrm{~h}+1200^{\circ} \mathrm{C} / 10$

These results show the variability and adaptability of the method. These cycles produced good material as shown from metallographic observation and mechanical property testing. 


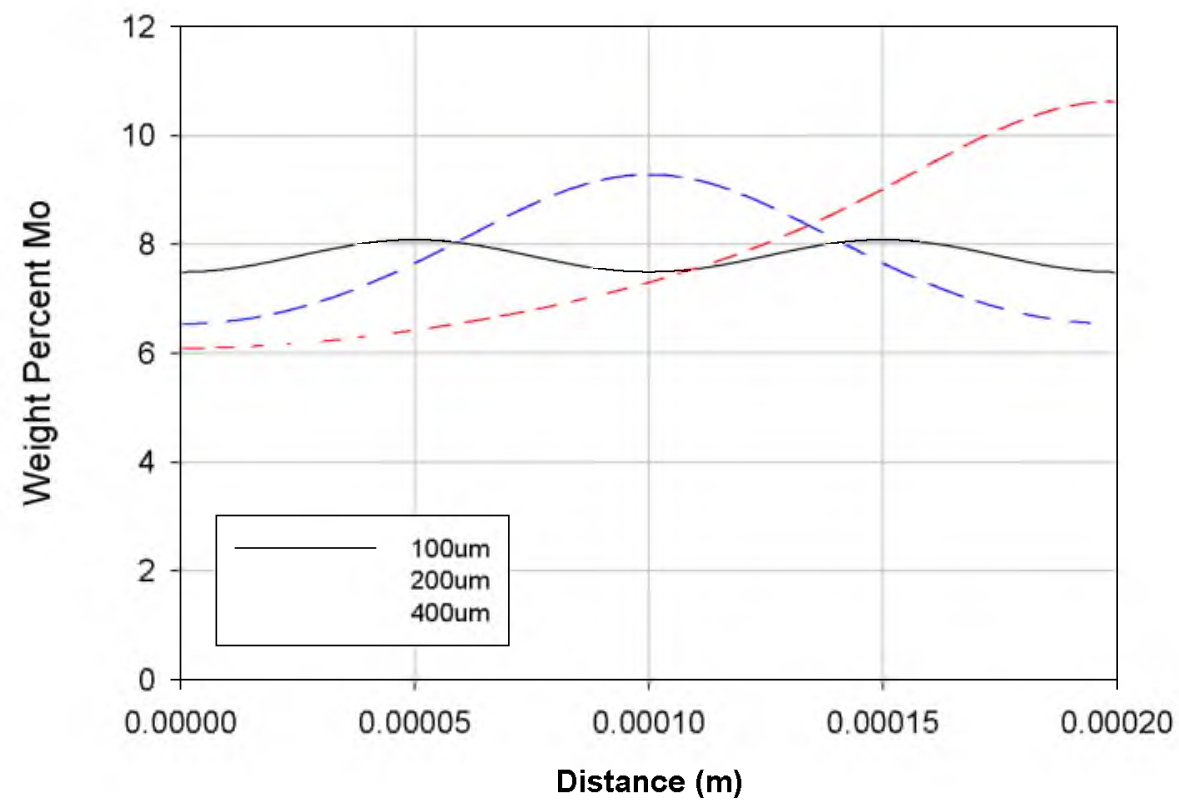

Figure 6: The molybdenum profile is shown for various sdas lengths for Haynes 282 after homogenizing at $1100^{\circ} \mathrm{C} / 3 \mathrm{~h}+1200^{\circ} \mathrm{C} / 9 \mathrm{~h}$.

Alloy 263 is another well-established Ni-base superalloy with a nominal composition of Ni$20 \mathrm{Cr}-20 \mathrm{Co}-5.85 \mathrm{Mo}-2.4 \mathrm{Ti}-0.3 \mathrm{Al}$ with small amounts of $\mathrm{C}$ and $\mathrm{B}$ as well as composition limitations on Fe, Mn and Si. Similar sized ingots to Haynes 282 (both large and small) were made from alloy 263 . The length scale of sdas in the small castings was approximately $100 \mu \mathrm{m}$, while that of the large castings was on the order of $200 \mu \mathrm{m}$. The homogenization cycles developed for alloy 263 were: $1100^{\circ} \mathrm{C} / 3 \mathrm{~h}+1200^{\circ} \mathrm{C} / 9 \mathrm{~h}$ (small castings); $1100^{\circ} \mathrm{C} / 1 \mathrm{~h}+1200^{\circ} \mathrm{C} / 4$ $\mathrm{h}+1250^{\circ} \mathrm{C} / 18 \mathrm{~h} ; 1100^{\circ} \mathrm{C} / 1 \mathrm{~h}+1190^{\circ} \mathrm{C} / 44 \mathrm{~h}$; and $1100^{\circ} \mathrm{C} / 1 \mathrm{~h}+1200^{\circ} \mathrm{C} / 4 \mathrm{~h}+1232^{\circ} \mathrm{C} / 22 \mathrm{~h}$ (large castings). Each homogenization cycle results in successful homogenization as evidenced by metallographic inspection and mechanical property determination.

Alloy 105 (or Nimonic 105) is yet another well-established Ni-base superalloy with a nominal composition of Ni-14.8Cr-20.0 Co-5.0Mo-1.2Ti-4.7Al with small amounts of $\mathrm{C}$ and $\mathrm{B}$ and limitations on $\mathrm{Cu}, \mathrm{Fe}, \mathrm{Mn}, \mathrm{Si}$ and $\mathrm{Zr}$. Small scale ingots of this alloy were produced with resultant maximum sdas $\leq 100 \mu \mathrm{m}$. The homogenization cycle used in this case was: $1100^{\circ} \mathrm{C} / 3 \mathrm{~h}$ $+1200^{\circ} \mathrm{C} / 9 \mathrm{~h}$. Good homogenization was achieved (see Figure 7). Figure 8 shows the resultant creep testing that was performed on the cast and homogenized alloy 105. As with the Haynes 282 alloy there was good correlation between wrought and cast/homogenized creep rupture lives for stress-temperature combinations. 

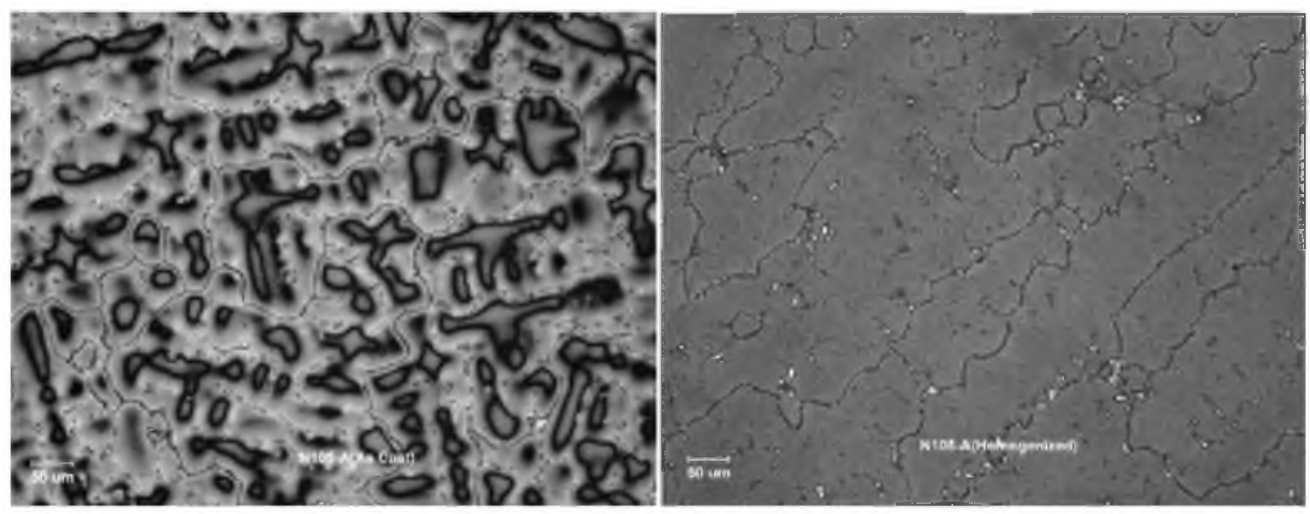

Figure 7: Examples of the as-cast (left) and homogenized (right) microstructure of Nimonic 105 are shown above. Dendritic coring is clearly visible on the left while only grain boundaries and carbides are visible on the right. Note that these two samples were in the same metallographic mount and prepared in an identical manner.

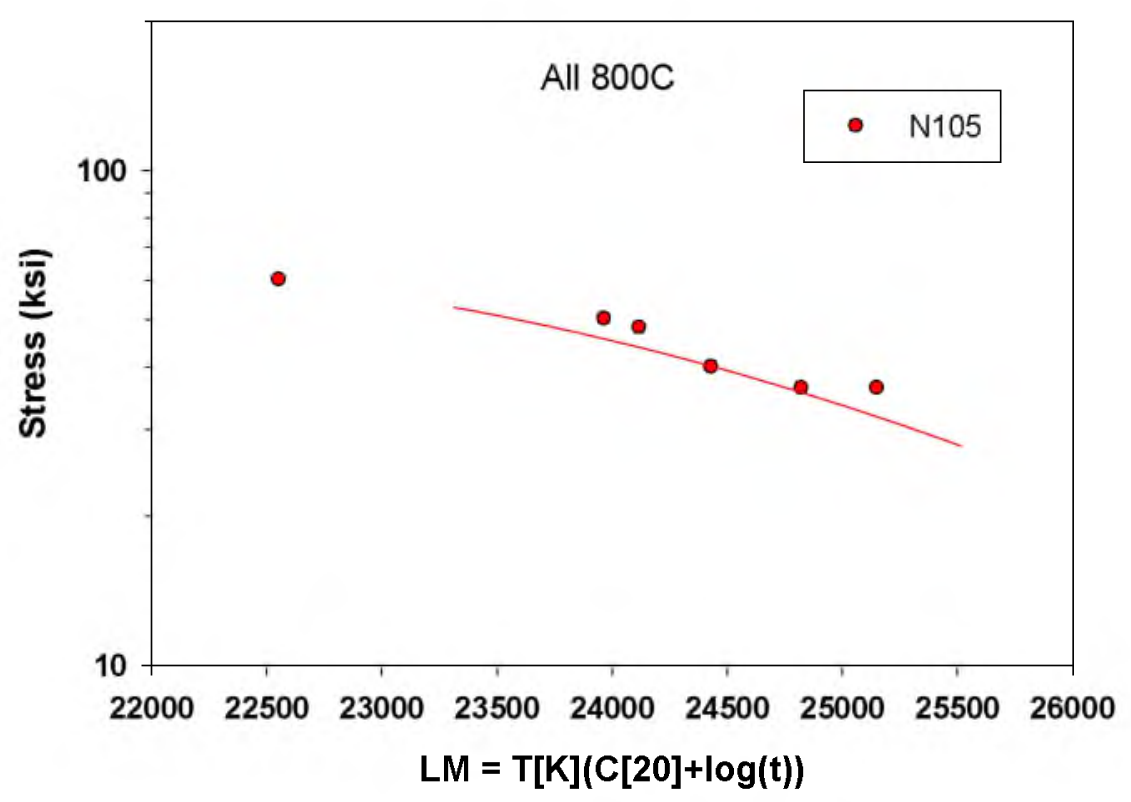

Figure 8: Larson-Miller plot comparing the cast and homogenized (closed circles) versus wrought versions of Nimonic 105 (solid line). Note that the cast and homogenized versions on Nimonic 105 compare favorably to wrought alloy performance.

\section{Discussion}

Obtaining good mechanical properties for cast nickel superalloys is very important in the power industry. For land based power plants that increase the temperature and pressure of the steam to $760^{\circ} \mathrm{C}$ and $34.5 \mathrm{MPa}$ requires materials with superior creep strength as expected life of these components must reach at least 100,000 hours, if not longer. Most nickel casting is in relatively thin sections compared to the turbine casing thickness. As such normal nickel superalloy casting techniques are not appropriate. Additionally, the slow cooling in these thick castings causes significant segregation that must be addressed. NETL examined the technology gap and approached it via a computationally based heat treatment cycle in which the sdas is used as a 
feature of merit in order to derive a multi-step homogenization process. A number of nickel superalloys were produced as castings and each casting was evaluated against its wrought product form.

It was possible to produce cast versions of each of the following: nickel solid solution strengthened superalloys $\left(230,617\right.$ and 625) as well as $\gamma^{\prime}$ strengthened nickel superalloys (105, 263,740 , and 282). Adding the homogenization step greatly reduced and/or eliminated alloy segregation due to thick section cooling from the melt. For the $\gamma^{\prime}$ strengthened alloys $(105,263$, and 282) subsequent aging heat treatments produced mechanical strength equivalent to the wrought product. This was especially evident in the creep rupture test results where life as measured by the Larson-Miller parameter was equivalent to the wrought values. On the other hand, for solution strengthened castings (230,617 and 625), there remained a debit in terms of creep performance compared to the wrought version of the alloy.

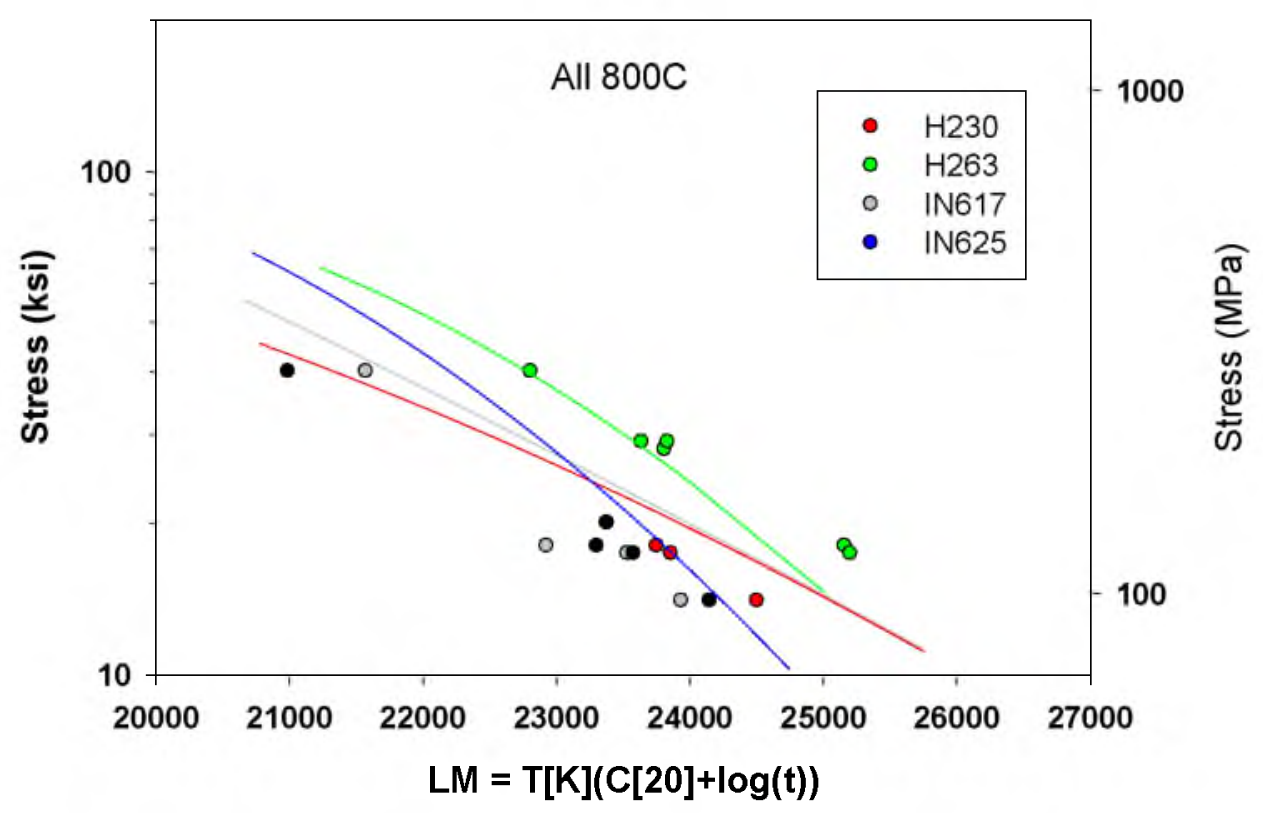

Figure 9: Larson-Miller plot comparing the cast and homogenized (closed circles) for solution strengthened superalloys (and 263) versus wrought versions of those same alloys (solid line). Note that the creep capability of the cast and homogenized versions of the solution strengthened superalloys is uniformly less than that of the wrought alloy performance.

The creep performance of the solution strengthened superalloys, as shown in Figure 9, clearly shows that creep capability is uniformly less than that of the wrought version of the corresponding alloy. This behavior is consistent with the differences that may result from an alloy not thermo-mechanically processed wherein stored energy of deformation is not available to induce recrystallization, and thereby, refine the grain size. In addition since there is little or no $\gamma^{\prime}$ precipitates in these alloys, the loss in strength from processing differences cannot be made up.

Although not shown here, tensile mechanical behavior at $800^{\circ} \mathrm{C}$ for the cast and homogenized superalloys was considered to be very good, especially in terms of ductility measures. Typically, elongation-to-failure for the solution strengthened cast and homogenized superalloys was $20 \%$ or greater, although one 230 tensile specimen showed a lower elongation at around $10 \%$. For the $\gamma^{\prime}$ 
strengthened alloys elongation to failure for tensile tests performed at $800^{\circ} \mathrm{C}$ was around $15 \%$ or greater for alloys 105, 263 and 282. Only alloy 740 performed at a level inconsistent with the other $\gamma^{\prime}$ strengthened alloys of similar volume fraction (notably alloy 282), with this cast alloy showing both lower than expected tensile strength and ductility (in terms of both elongation to failure and reduction in area). At this time there is no clear explanation as to why this might be the case.

A number of other observations were made during the course of modeling simulations, experimental manufacturing, and verification activities. During the computational modeling activities it was found that certain refractory elements, including $\mathrm{W}$, $\mathrm{Mo}$, and $\mathrm{Nb}$, do not homogenize even after $\sim 22$ hours at $1100^{\circ} \mathrm{C}$. This was the main motivation for exploring and developing a computational multi-step homogenization heat treatment schedule. Also, it was observed during optical microscopy and SEM of the cast structures that segregation of the second phase strengthening elements, including $\mathrm{Al}, \mathrm{Nb}$ and $\mathrm{Ti}$, consistently occurred in these alloys, to the point that $1 / 2$ to $2 / 3$ of the casting could be considered "lean". It was also during these early microstructural investigations that $\mathrm{Cr}$ poor regions were discovered in the solidified casting as predicted by the thermodynamic modeling activities. In addition, in selected alloys significant $\mathrm{Co}$ segregation was predicted. Thermodynamic modeling also suggested that significant partitioning of $\mathrm{Mn}$ and $\mathrm{Si}$ to the interdendritic region might occur. These many factors made apparent the need to homogenize these materials since to one degree or another, some or all of the above factors came into play for each of the nickel superalloys. To produce consistent tensile and creep properties it was felt that at the very least a more uniform microstructure in terms of the chemical distribution of elements was needed. Other anomalies, such as shrinkage, voids and other manufacturing anomalies, consistent with melt-solidification of castings, still occurred. These manufacturing related anomalies can be cleared up through better melting practice.

\section{Conclusions}

With modifications to alloy chemistry to improve liquid metal castability, it was possible to produce thick section casting of wrought superalloys, both solution and $\gamma^{\prime}$ strengthened versions. In addition the application of a carefully controlled multi-step homogenization procedure, based on thermodynamics, kinetics and sdas measurements, was used to reduce significantly, or eliminate altogether, visible segregation in the castings. As a consequence tensile mechanical properties and creep rupture life were greatly improved as were particular measures of ductility. Creep capability for the $\gamma^{\prime}$ strengthened nickel superalloys was equivalent to that of the wrought version with data superposed on the mean of the wrought tests for Haynes alloys 263 and 282 and Nimonic 105. Solution strengthened superalloys (i.e., alloys 230, 617 and 625), while performing well in the cast and homogenized condition, did not perform to the same level as their wrought counterpart.

\section{Acknowledgments}

The authors wish to acknowledge the assistance of Edward Argetsinger (melting and casting) and Paul Danielson (metallography and optical microscopy). Paul Mason, Zi-Kui Liu, Qing Chen, and John Ågren provided many helpful suggestions with the use of ThermoCalc and DICTRA software. This work was performed as part of the U.S. DOE/OCDO A-USC Steam Turbine Consortium. Special thanks are given to R. Viswanathan, J.P Shingledecker, R. Purgert, P. Rawls, R. Romanowski, and M. Marrocco for their leadership and support of the program. 


\section{Disclaimer}

This report was prepared as an account of work sponsored by an agency of the United States Government. Neither the United States Government nor any agency thereof, nor any of their employees, makes any warranty, express or implied, or assumes any legal liability or responsibility for the accuracy, completeness, or usefulness of any information, apparatus, product, or process disclosed, or represents that its use would not infringe privately owned rights. Reference herein to any specific commercial product, process, or service by trade name, trademark, manufacturer, or otherwise does not necessarily constitute or imply its endorsement, recommendation, or favoring by the United States Government or any agency thereof. The views and opinions of authors expressed herein do not necessarily state or reflect those of the United States Government or any agency thereof.

\section{References}

1. G.L. Erickson, "The Development and Application of CMSX-10," Superalloys, R.D. Kissinger, D.J. Deye, D.L. Anton, A.D. Cetel, M.V. Nathan, T.M. Pollock and D.A. Woodford, Eds. (Warrendale, PA: TMS, 1996) 35-44.

2. E.C. Caldwell, F.J. Fela and G.E. Fuchs, "Segregation of Elements in High Refractory Content Single Crystal Nickel Based Superalloys," Superalloys, K.A. Green, T.M. Pollock, H. Harada, T.E. Howson, R.C. Reed, J.J. Schirra and S. Walston, Eds. (Warrendale, PA: TMS, 2004) 811-818.

3. S.R. Hedge, R.M. Kearsey and J.C. Beddoes, "Designing Homogenization-Solution Heat Treatments for Single Crystal Superalloys," Mater. Sci. Eng. A, 527 (2010) 558-5538.

4. W.S. Walston, J.C. Schaeffer and W.H. Murphy, "A New Type of Microstructural Instability in Superalloys-SRZ," Superalloys, R.D. Kissinger, D.J. Deye, D.L. Anton, A.D. Cetel, M.V. Nathan, T.M. Pollock and D.A. Woodford, Eds. (Warrendale, PA: TMS, 1996) 9-18.

5. C.J. Burton, "Differential Thermal Analysis and the Mechanisms of Minor Additions in Superalloys," Superalloys, D.R. Muzyka, W.H. Counts, G.E. Waseilewsky, B.H. Kear, J.P. Stroup, R.L. Dreshfield and H. Morrow, Eds. (Warrendale, PA: TMS, 1976) 147157.

6. D.L. Sponseller, "Differential Thermal Analysis of Nickel-Base Superalloys," Superalloys, R.D. Kissinger, D.J. Deye, D.L. Anton, A.D. Cetel, M.V. Nathan, T.M. Pollock and D.A. Woodford, Eds. (Warrendale, PA: TMS, 1996) 259-266.

7. G.E. Fuchs, "Solution Heat Treatment Response of a Third Generation Single Crystal Nibase Superalloy," Mater. Sci. Eng. A, 300 (2001) 52-60. 
8. S.A. Sajjadi, S.M. Zebarjid, R.I.L. Guthrie and M. Isac, "Microstructure Evolution of High-Performance Ni-base Superalloy GTD-111 with Heat Treatment Parameters," J. Mater. Process. Technol., 175 (2006) 376-381.

9. J.W. Martin, R.D. Doherty and B. Cantor, Stability of Microstructure in Metallic Systems, $2^{\text {nd }} E d$. (Cambridge, UK: Cambridge University Press, 1997) 28.

10. D.A. Porter and K.E. Easterling, Phase Transformation in Metals and Alloys (New York, NY: Van Nostrand Reinhold Co., 1981) 215.

11. P.G. Shewmon, Recrystallization, Grain Growth and Textures (Metals Park, OH: Chapman and Hall, 1966) 165.

12. G.R. Purdy and J.S. Kirkaldy, "Homogenization by Diffusion," Metall. Trans., 2 (1971) 371-378.

13. J.W. Martin, R.D. Doherty and B. Cantor, Stability of Microstructure in Metallic Systems, $2^{\text {nd }}$ Ed. (Cambridge, UK: Cambridge University Press, 1997) 41.

14. R.G. Ward, "Effect of Annealing on the Dendritic Segregation of Manganese in Steel," $J$. Iron Steel Inst., 203 (1965) 930-932.

15. F. Weinberg and R.K. Buhr, "Homogenization of a Low-Alloy Steel," J. Iron Steel Inst., 207 (1969) 1114-1121.

16. F.C. Quigley and P.J. Ahearn, "Homogenization of High-Strength Steel at 2500F," No. AMRA-TR-64-42 (Watertown, MA: Army Materials Research Agency, 1964).

17. J.W. Martin, R.D. Doherty and B. Cantor, Stability of Microstructure in Metallic Systems, $2^{\text {nd }} E d$. (Cambridge, UK: Cambridge University Press, 1997) 43.

18. J.W. Martin, R.D. Doherty and B. Cantor, Stability of Microstructure in Metallic Systems, $2^{\text {nd }}$ Ed. (Cambridge, UK: Cambridge University Press, 1997) 46-47.

19. A. Kohn and J. Doumerc, Memoires Scientifiques de la Revue de Metallurgie, 53 (1955) 249.

20. R.W. Heckel and M. Balasubramanian, "The Effects of Heat Treatment and Deformation on the Homogenization of Compacts of Blended Powders," Metall. Trans., 2 (1971) 379391.

21. THERMOCALC, Version 3.1 (Stockholm, Sweden: Royal Institute of Technology, 2013) 
22. DICTRA, Version 27 (Stockholm, Sweden: Royal Institute of Technology, 2008).

23. Ni-DATA, Version 27 (Surrey Technology Centre, UK: Sente Software Ltd., 2005).

24. E. Scheil, "Bemerkungen zur schichtkristallbildung," Z. Metallkd., 34 (1942) 70-72 (in German).

25. G.H. Gulliver, "The Quantitative Effect of Rapid Cooling Upon the Constitution of Binary Alloys," J. Inst. Met., 9 (1913) 120-57.

26. P.D. Jablonski, J.A. Hawk, C.J. Cowen and P.J. Maziasz, "Processing of Advanced Alloys for A-USC Steam Turbine Applications," Proc. $6^{\text {th }}$ International Conference on Advances in Materials Technology for Fossil Power Plants, D. Gandy, J.P. Shingledecker and R. Viswanathan, Eds. (Palo Alto, CA: Electric Power Research Institute, 2010) 872885 .

27. P.D. Jablonski, J.A. Hawk, C.J. Cowen and P.J. Maziasz, "Processing of Advanced Cast Alloys for A-USC Steam Turbine Applications," Journal of Metals, 64 (2012) 271-279. 